\title{
Rate of Dissolution of Solid Iron in a Carbon-saturated Liquid Iron Alloy with Evolution of CO*
}

\author{
By Kazumi MORI** and Toshikazu SAKURAYA***
}

\section{Synopsis}

Studies have been made on the rates of dissolution of stationary or rotated cylindrical iron specimens containing various amounts of oxygen into molten carbon-saturated iron alloys. The explored temperature range was from $1200^{\circ} \mathrm{C}$ to $1450^{\circ} \mathrm{C}$. The highest oxygen concentration of the specimen was $1.14 \%$. The dissolution rate was determined from the rate of decrease in diameter of the cylinder.

In the case of stationary dissolution, oxygen in the iron specimen, that is, the evolution of $\mathrm{CO}$ was found to have a marked effect on the dissolution rate. This phenomenon is shown to be analogous to the mass transfer at a gas evolving electrode. At high oxygen contents of the specimen, a phenomenon analogous to nucleate-film boiling of liquid over a hot solid surface was observed. The highest dissolution rate which was observed at $1400^{\circ} \mathrm{C}$ for iron containing $0.96 \%$ oxygen is 590 times as large as the lowest rate observed at $1200^{\circ} \mathrm{C}$ for aluminum-killed iron.

In the case of rotational dissolution of iron specimens containing oxygen, at lower rpm the rate is controlled mainly by the extent of $\mathrm{CO}$ evolution. At higher rpm, the effect of rotation becomes predominant.

\section{Introduction}

During the last two decades, dissolution of solid iron into liquid iron-carbon alloys has been studied from both theoretical and practical points of view. Scrap melting is one of the most interesting practical problems in which mass transfer in the dissolution of solids into liquids plays a role of significance.

Quite recently, new technologies have been developed in which dissolution of solids into liquids accompanied with evolution of gas bears an important meaning in determining process kinetics. Typical examples of these technologies are melting of prereduced iron particles in electric arc steelmaking and smelting reduction of iron oxide in iron-carbon alloy melts. Reduction of $\mathrm{Cr}_{2} \mathrm{O}_{3}$ by carbon in the refining process of high chromium steel falls under the present category. Studies on the kinetics and mechanism of solid dissolution with evolution of gas, though important and interesting, have never been reported.

The present study has been undertaken to obtain knowledge on the rate of solid dissolution with gas evolution in high temperature metallurgical systems. The experiments consisted of measuring the rate of dissolution of iron cylinders containing various amounts of oxygen immersed in the melt of carbonsaturated iron. During dissolution CO was evolved from the reaction between carbon in the melt and oxygen in the iron specimen. The cylindrical specimen was stationary in one series of experiments; in another series it was rotated.

\section{Experimental}

\section{Apparatus}

Figure 1 is a schematic drawing of the experimental apparatus. The heating element was a $80 \mathrm{~mm}$ in ID silicon carbide tube of spiral type. Along the center of the furnace was an alumina reaction tube $52 \mathrm{~mm}$ in ID and $800 \mathrm{~mm}$ long. A graphite crucible, 40 $\mathrm{mm}$ in ID and $125 \mathrm{~mm}$ in height, was set in the reaction tube.

Above the furnace was equipped an assembly for holding and rotating the solid specimen. The specimen was fitted into a graphite rod and connected to the holding assembly by a stainless steel rod. Direct contact between the specimen and the graphite rod was prevented by using alumina paste.

Temperature of the melt was controlled by using two Pt-Rh thermocouples: one was set just outside the furnace tube and the other was in the base of the crucible. During experiments argon gas flowed inside the reaction tube at a rate of $700 \mathrm{~cm}^{3} / \mathrm{min}$.

\section{Specimens}

The starting material of specimens was iron ingots containing various amounts of oxygen. Cylindrical specimens of $12 \mathrm{~mm}$ in diameter and $70 \mathrm{~mm}$ in length were prepared from the ingots through rolling, ma-

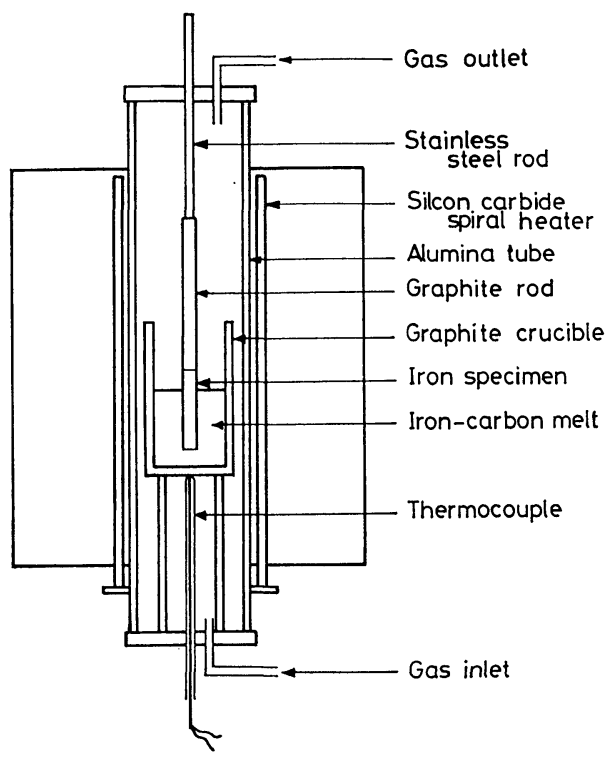

Fig. 1. Schematic drawing of experimental apparatus.

\footnotetext{
* Presented to the 92nd ISIJ Meeting, October 1976, at Tohoku Institute of Technology in Sendai, and to the 93rd ISIJ Meeting, April 1977, at The University of Tokyo in Tokyo. Manuscript received January 18, 1982. (C) 1982 ISIJ

** Department of Iron and Steel Engineering, Nagoya University, Furo-cho, Chikusa-ku, Nagoya 464.

*** Technical Research Center, Kawasaki Steel Corporation, Kawasaki-cho, Chiba 260.
} 
chining and polishing. The ranges of composition of the specimens are shown in Table 1.

Additionally, specimens containing larger amounts of oxygen were prepared from pure iron powder. Iron powder with desired amount of oxygen was sintered to form a cylinder, which was then subjected to forging.* The forged cylinder was machined to the prescribed specimen size. The oxygen contents of the specimens were varied as $0.65,0.96$ and $1.14 \%$.

Photograph 1 shows the distribution of iron-oxide inclusions at the transverse cross-sections of the cylindrical iron specimens.

\section{3. $\quad$ Procedures}

In a typical experiment, a $550 \mathrm{~g}$ of carbon-saturated iron alloy was charged into the crucible and the cylindrical iron specimen was positioned at the upper part of the reaction tube. After the charge was melted and the melt temperature reached the desired level, the iron specimen was lowered to $5 \mathrm{~mm}$ above the surface of the liquid bath and preheated for about 10 min. Then, the specimen was immersed approximately $55 \mathrm{~mm}$ into the melt for a predetermined period of time. After withdrawing the specimen from the melt, the specimen was quenched in water.

In the case of rotational dissolution, rotation of the specimen was started at the instant the specimen was immersed into the melt.

Dissolution rate of the cylindrical specimen was determined from the rate of decrease in diameter of the cylinder. The cylinder diameter was measured at 5 distances along the axis of the cylinder. At each distance, the measurement was made at 2 to 4 points. From the measurements at all points, an average value of diameter was obtained to calculate the dissolution rate.

Experiments for stationary dissolution were carried out with iron specimens of 11 varieties of oxygen content and over the temperature range from 1200 to $1450{ }^{\circ} \mathrm{C}$. The experimental conditions for rotational dissolution were rather limited.

\section{Mass Transfer during Solid Dissolution}

It has been well established that the rate-controlling step in the isothermal dissolution of solid iron into liquid iron-carbon alloys is mass transfer in the liquidside boundary layer. During the dissolution process, carbon atoms in the bulk iron-carbon melt diffuse to the solid-liquid interface to maintain equilibrium between solid and liquid carbon concentrations.

The dissolution rate, $v$, is represented by the rate of motion of the solid-liquid interface $(-d r / d t)$. Here,

Table 1. Chemical composition of iron specimens.

\begin{tabular}{|c|c|c|c|c|c|c|c|}
\hline & \multicolumn{7}{|c|}{ Composition (\%) } \\
\hline & G & $\mathrm{Si}$ & $\mathrm{Mn}$ & $\mathrm{P}$ & $\mathrm{S}$ & $\mathrm{Al}$ & $\mathrm{O}$ \\
\hline Al-killed & \multirow{2}{*}{$0.002 \sim 0.005$} & \multirow{2}{*}{$0.001 \sim 0.005$} & \multirow{2}{*}{$0.001 \sim 0.003$} & \multirow{2}{*}{$0.003 \sim 0.004$} & \multirow{2}{*}{$0.002 \sim 0.005$} & 0.013 & $0.0025^{*}$ \\
\hline $\mathrm{Fe}-\mathrm{O}$ & & & & & & $0 \sim 0.001$ & $0.005 \sim 0.17$ \\
\hline
\end{tabular}

* Concentration of oxygen combined with aluminum

140

1100

Photo. 1. Distribution of $\mathrm{FeO}$ inclusions at transverse sections of iron specimens. Numbers on side indicate oxygen concentration in ppm.

* Oxygen was given by heating the iron powder in an oxidizing atmosphere. 
$r$ is the specimen radius. For the dissolution of a solid iron cylinder of carbon concentration, $C_{S}$ into a liquid iron-carbon alloy of carbon concentration, $C_{L}$, the following mass transfer equation of dissolution rate, is given by Lommel and Chalmers ${ }^{1)}$

$$
v=k \ln \left(1+\frac{C_{L}-C_{L}^{*}}{C_{L}^{*}-C_{S}}\right)
$$

where $C_{L}^{*}$ is carbon concentration in the liquid at the interface and $k$ is the mass transfer coefficient. Experimental data for both the stationary and rotational dissolutions will be treated by using Eq. (1).

During dissolution of specimens containing oxygen, the reaction of carbon and oxygen producing $\mathrm{CO}$ bubbles is considered to take place in the liquid adjacent to the solid-liquid interface because of much lower concentration of oxygen in the liquid as compared with that of carbon. Therefore, the effect of bubble formation on the mass transfer rate will be reflected on the value of mass transfer coefficients.

\section{Stationary Dissolution}

\section{Specimen Shape}

Photograph 2 shows typical appearances of cylindrical iron specimens partially dissolved into carbonsaturated iron melts at $1400{ }^{\circ} \mathrm{C}$. There are three varieties of the specimen shape.

When no gas evolution occurs during immersion of the specimen, the specimen has the shape of a frustum of a cone (Photo. 2(a)). This shape is a reflection of the change of dissolution rate along the specimen axis, as well explained by Kim and Pehlke. ${ }^{2)}$ The liquid near the iron specimen surface moves downward during dissolution. At the lower part of the specimen, the thickness of the diffusion boundary

\section{$\longmapsto 1 \mathrm{~cm}$}

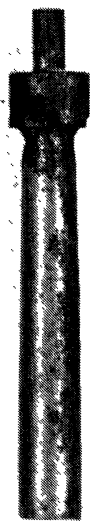

(a)

$\mathrm{O}(\mathrm{ppm})$

Immersion time (s)

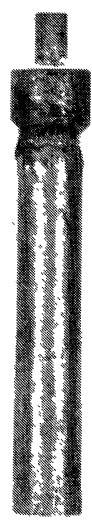

(b)

50

25

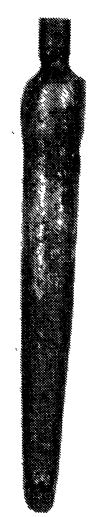

(c)

1700 9
Photo. 2. Appearance of iron specimens after stationary dissolution into molten carbon-saturated iron at $1400^{\circ} \mathrm{G}$. layer becomes thicker and hence the dissolution rate becomes smaller.

Evolution of $\mathrm{CO}$ gas during dissolution of the specimen containing oxygen brings about a drastic change in the shape of the specimen. The liquid in the vicinity of the specimen surface contains CO bubbles and tends to move upward due to the gas lift effect. As is evident from the boundary layer theory, the diffusion boundary layer in the liquid flowing upward along the specimen surface becomes thicker at the upper part. The dissolution rate decreases toward the upper part of the specimen. This phenomenon is well illustrated in Photo. 2(c) for the case of high oxygen content of the specimen and hence intense formation of $\mathrm{CO}$ bubbles.

When the evolution of $\mathrm{CO}$ bubbles is moderate, it just suppresses the downward liquid flow which would occur if the specimen did not contain oxygen and dissolved with natural convection. Photograph 2(b) corresponds to this case.

\section{Dissolution Rate}

Figures 2 and 3 show typical examples of the change of the diameter in the dimensionless form $\left(d / d_{0}\right)$ with the immersion time for various oxygen contents of the specimens. Here, $d_{\mathbf{0}}$ is the initial specimen diameter. Except for the case of 11400 ppm O (Fig. 2), the

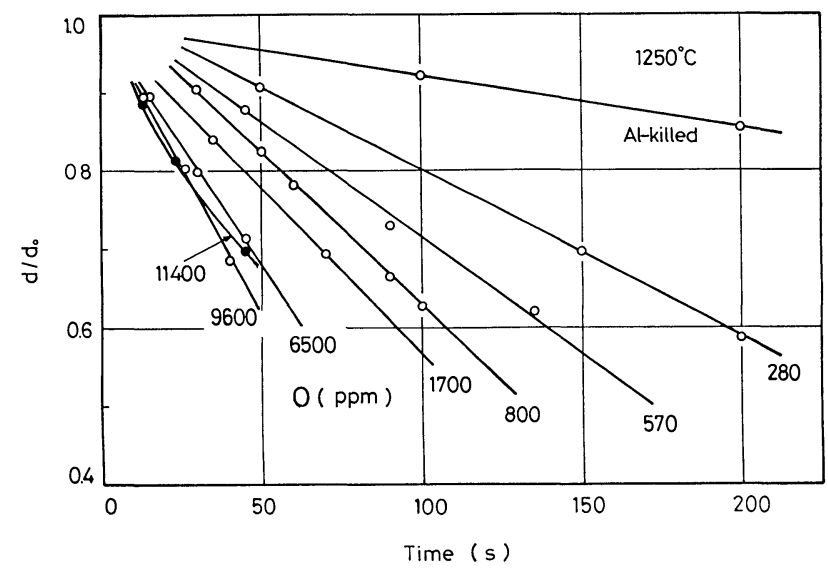

Fig. 2. Stationary dissolution of iron of various oxygen contents into molten carbon saturated iron at $1250^{\circ} \mathrm{G}$.

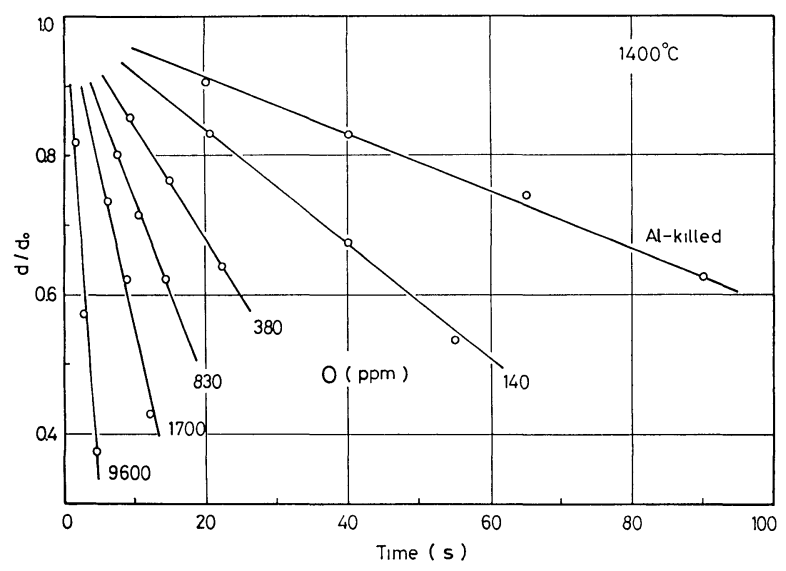

Fig. 3. Stationary dissolution of iron of various oxygen contents into molten carbon-saturated iron at $1400^{\circ} \mathrm{G}$. 
diameter decreases linearly with immersion time and the dissolution rate represented by $-d r / d t$ is constant.

As seen from Figs. 2 and 3, oxygen in the iron specimen has a marked effect on the dissolution rate. The dissolution mass transfer rate is considerably accelerated by $\mathrm{CO}$ evolution.

\section{Relation between the Mass Transfer Coefficient and Rate of $\mathrm{CO}$ Evolution}

From the dissolution rates, $v$, the mass transfer coefficients, $k$, are calculated by using Eq. (1) for various oxygen contents of the specimens and experimental temperatures. In Fig. $4{ }^{*}$ the mass transfer coefficient is plotted against the oxygen content of the iron specimens for various experimental temperatures. The mass transfer coefficient for the dissolution of iron containing about $1 \%$ oxygen is one order of magnitude larger than that for aluminum-killed iron. At higher temperatures, the mass transfer coefficient increases with increasing the oxygen content or iron specimens to a larger extent. The lowest value observed is $1.15 \times 10^{-3} \mathrm{~cm} / \mathrm{s}$ for aluminum-killed iron at $1200^{\circ} \mathrm{C}$. The highest value is $8.4 \times 10^{-2}$ $\mathrm{cm} / \mathrm{s}$ for iron containing $0.96 \%$ oxygen at $1400^{\circ} \mathrm{C}$ and 73 times as large as the former value at $1200^{\circ} \mathrm{C}$.
The dissolution rate in the latter case, that is at 1400 ${ }^{\circ} \mathrm{C}$, is 590 times as large as that in the former case.

The mass transfer is determined by the convective flow originated from bubble generation in the liquid near the cylindrical specimen surface. The flow may be caused by detaching and rising of bubbles and by coalescence of bubbles. These behaviors of bubbles enhancing the mass transfer rate depend on the physical properties of the liquid as well as the extent of $\mathrm{CO}$ evolution during dissolution.

The rate of $\mathrm{CO}$ evolution per unit area of the specimen surface, $\dot{V}_{\mathrm{CO}}\left(\mathrm{cm}^{3} / \mathrm{cm}^{2} \cdot \mathrm{s}\right)$, may be given from the dissolution rate and oxygen content of the specimen as

$$
\begin{aligned}
\dot{V}_{\mathrm{CO}}= & \rho_{\text {iron }} \times(\mathrm{ppm} \mathrm{O}) \times 10^{-6} \times\left(-\frac{d r}{d t}\right) \times \frac{1}{16} \\
& \times 2.24 \times 10^{4} \times\left(\frac{T+273}{273}\right) \ldots \ldots \ldots \ldots \ldots \ldots \ldots
\end{aligned}
$$

where, $\quad \rho_{\text {iron }}$ : density of solid iron $\left(\mathrm{g} / \mathrm{cm}^{3}\right)$

(ppm 0): oxygen concentration of iron specimen

$-d r / d t$ : dissolution rate $(\mathrm{cm} / \mathrm{s})$

$T$ : experimental temperature $\left({ }^{\circ} \mathrm{G}\right)$.

In Fig. 5, the mass transfer coefficient is plotted
Fig. 4. Mass transfer coefficient vs. oxygen concentration for stationary dissolution at various temperatures.

Fig. 5. Mass transfer coefficient vs. CO evolution rate for stationary dissolution at various temperatures.
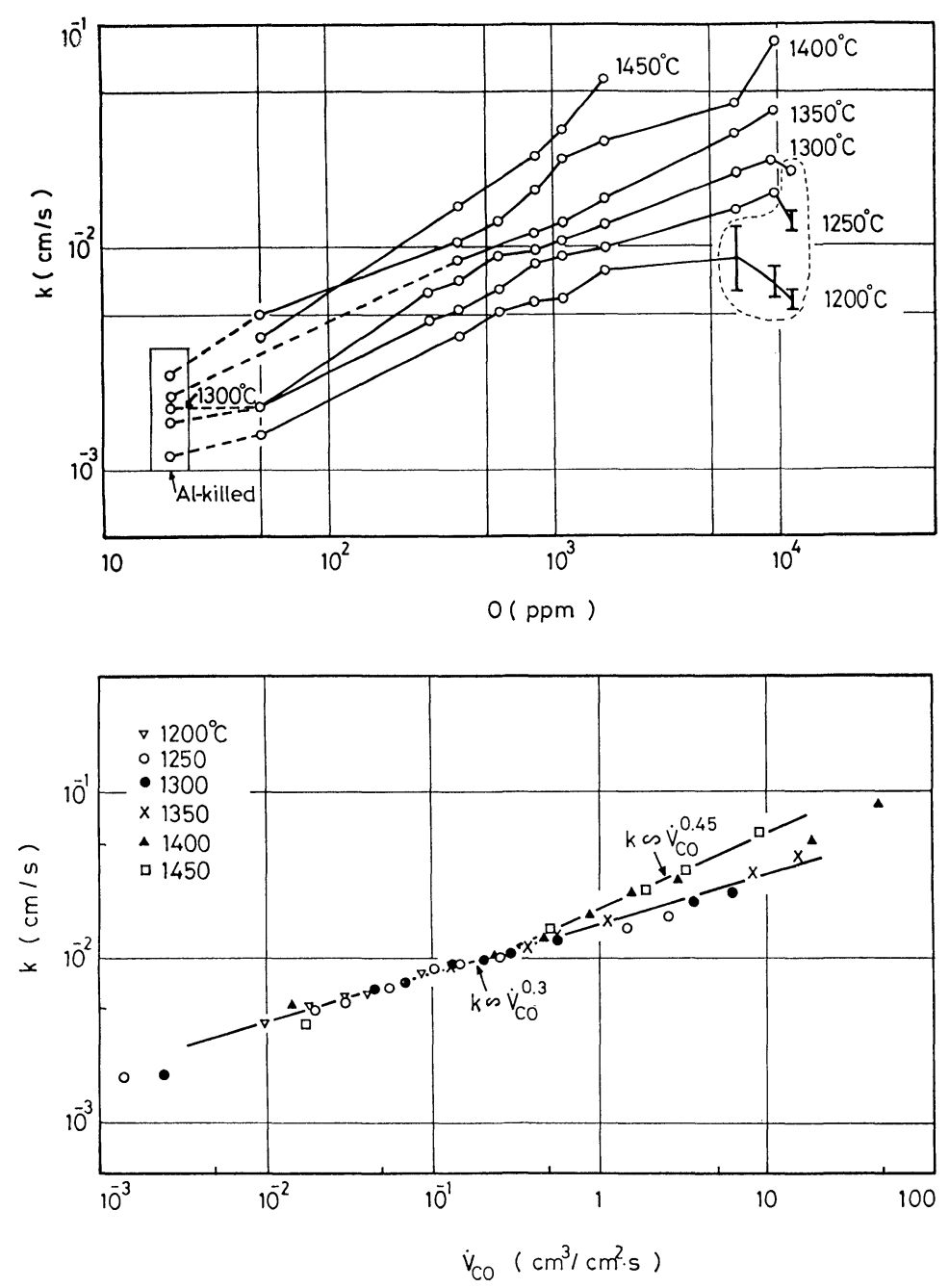

\footnotetext{
* There is some scatter in the mass transfer coefficient obtained for iron containing 50 ppm oxygen. This may be due to a difficulty in obtaining accurate values of rate of the dissolution which was rather unstable at $50 \mathrm{ppm}$ oxygen.
} 
against $\dot{V}_{\mathrm{co}}$. For $\dot{V}_{\mathrm{CO}}<10^{-2} \mathrm{~cm}^{3} / \mathrm{cm}^{2} \cdot \mathrm{s}$, data points are insufficient to find any significant correlation. At $\dot{V}_{\mathrm{Co}}>10^{-2} \mathrm{~cm}^{3} / \mathrm{cm}^{2} \cdot \mathrm{s}$, the mass transfer coefficient increases with the rate of $\mathrm{CO}$ evolution to a power of 0.3 in the range of lower temperatures. At 1400 and $1450{ }^{\circ} \mathrm{C}$ the mass transfer coefficient increases with increasing $\dot{V}_{\text {co }}$ to a larger extent than that expressed by the power of 0.3 . In this case a correlation represented by $\mathrm{k} \infty \dot{V}_{\mathrm{CO}}^{0.45}$ is obtained at $\dot{V}_{\mathrm{CO}}<10$ $\mathrm{cm}^{3} / \mathrm{cm}^{2} \cdot \mathrm{s}$.

The phenomena occurring in the present case of solid dissolution influenced by bubble generation are analogous to the mass transfer at a gas evolving electrode. The latter subject has been extensively studied by electrochemists. ${ }^{3-5)}$ Sigrist et al., ${ }^{5)}$ from their study on mass transfer in electrolytic cells with gas sparging, deduced that the mass transfer coefficient at gas evolving electrodes is proportional to the current density raised to the $1 / 3$ power. Janssen, ${ }^{4)}$ from a study on mass transfer at a gas evolving electrode, obtained correlations between diffusion layer thickness, $\delta$, and the volume rate of the gas evolution, $\dot{v}$. He concluded that, the slope of the $\log \delta / \log \dot{v}$ curve is low and about -0.3 when no coalescence of gas bubbles occurs, while that is high and about -0.9 when coalescence occurs frequently.

A similar explanation may be given to the present results. When the temperature was low, evolution of bubbles was not detected near the specimen surface. This may be due to the smallness of the bubbles. However, at 1400 and $1450{ }^{\circ} \mathrm{C}$, large bubbles were observed to evolve very frequently near the specimen surface. Thus, the behaviors of CO bubbles are considered to be responsible for the difference in the value of the exponent, such as 0.3 at lower temperatures and 0.45 at higher temperatures.

In Fig. 4, the data points encircled by a dotted line is to be noted. It is shown that at lower temperatures the mass transfer coefficient tends to decrease at high oxygen contents of the iron specimen. When iron of high oxygen content dissolves, a large number of nucleation sites are supplied to form numerous bubbles. If the bubbles do not detach very rapidly from the region near the specimen surface, coalescence of bubbles can occur.* This may lead to forming a blanketing layer on the specimen surface, resulting in the decrease in the mass transfer coefficient.** This phenomenon is very much analogous to nucleate-film boiling of liquid over a hot solid surface.

\section{Rotational Dissolution}

Experiments on the dissolution of rotated specimens were carried out for aluminum-killed iron at 1200 , 1250 and $1350{ }^{\circ} \mathrm{C}$ and for oxygen containing iron at $1250^{\circ} \mathrm{C}$. The rotational speeds were varied as 95 , 250, 500 and $900 \mathrm{rpm}$.
Typical appearances of partly dissolved iron specimens are shown in Photo. 3. The shape of the specimen rotationally dissolved is generally cylindrical independently of whether gas evolution occurs or not. At high rotational speeds, when gas evolution did not occur in the case of aluminum-killed iron, grooves were formed around the cylinder. When gas evolution occurred, the surface after dissolution was rather smooth, although fine grooves were still formed.

Figure 6 shows the plots of dimensionless specimen diameter $\left(d / d_{0}\right)$ against time for dissolution with gas evolution at various rotational speeds. Linear rela-

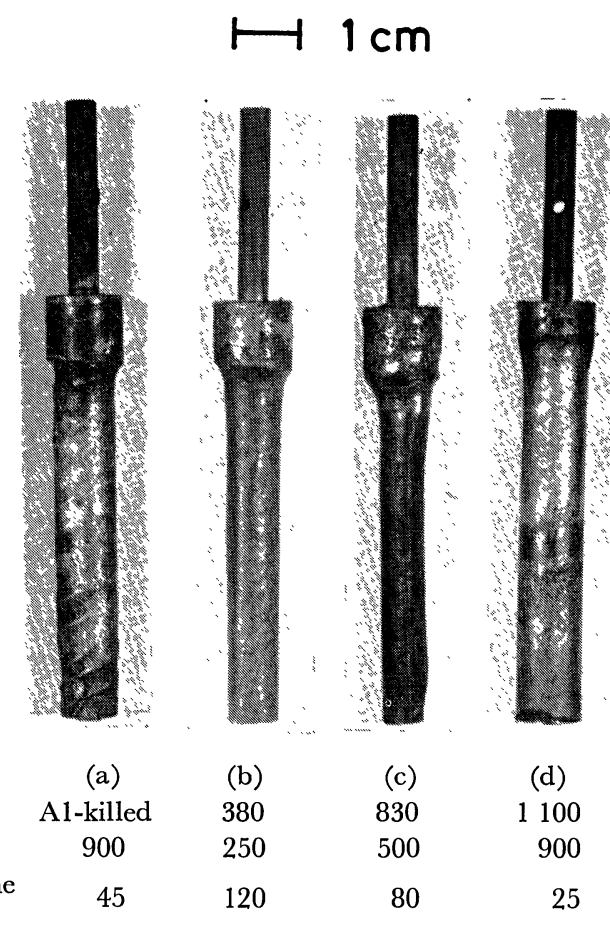

$\begin{array}{lccrr} & & (\mathrm{c}) & (\mathrm{d}) \\ \mathrm{O}(\mathrm{ppm}) & \text { A1-killed } & 380 & 830 & 1100 \\ \mathrm{rpm} & 900 & 250 & 500 & 900 \\ \begin{array}{c}\text { Immersion } \\ \quad(\mathrm{s})\end{array} & 45 & 120 & 80 & 25\end{array}$

Photo. 3. Appearance of iron specimens after rotational dissolution into molten carbon-saturated iron at $1250^{\circ} \mathrm{C}$.

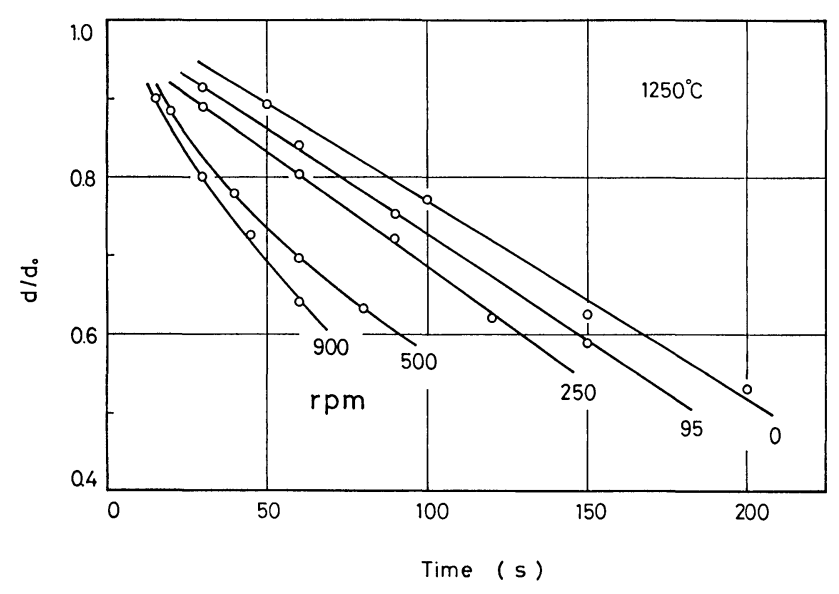

Fig. 6. Rotational dissolution of iron cylinder containing $380 \mathrm{ppm}$ oxygen into molten carbon-saturated iron at $1250^{\circ} \mathrm{C}$.

* It is highly possible that detaching of bubbles at lower temperatures is less active because of higher liquid viscosity than at higher temperatures.

** The observed scatter in the data, shown in Fig. 4 at high oxygen contents, is probably due to the instability in the dissolution process influenced by the formation of the blanketing layer. 
tionship is shown, except at 500 and $900 \mathrm{rpm}$. At these higher rotational speeds, the dissolution rate is mainly determined by the rotation of the specimen. During the dissolution process, the peripheral speed which determines the boundary layer thickness decreases gradually, leading to the decrease in the dissolution rate. In this case, the rate data in the early stage were used in the determination of the mass transfer coefficient.

To compare the present result of rotational dissolution without gas evolution with other studies, nondimensional correlation for mass transfer is shown in Fig. 7. Here, the mass transfer $J$-factor

$$
J_{d}=(k / u) S c^{0.644}
$$

is plotted against Reynolds number. Here, $u$ is the peripheral velocity and $S c$ is the Schmidt number. In obtaining the correlation, the physical properties of the liquid iron-carbon alloy are taken from the literature. ${ }^{7,8)}$

As shown in Fig. 7, the present result is in agreement with that of Kim and Pehlke, ${ }^{2)}$ although the present data are not enough to obtain a new correlation equation.

In Fig. 8, the mass transfer coefficient at $1250^{\circ} \mathrm{C}$ is plotted against the rotational speed for various oxygen contents of the specimens. The mass transfer coefficient for aluminum-killed iron increases markedly with increasing rpm. At higher oxygen contents of the specimen, the mass transfer coefficient is virtually constant in the range of rpm below a certain value $(\mathrm{rpm}<250)$. At $\mathrm{rpm}>250$, however, the mass transfer coefficient increases with increasing rpm and tends to be independent of oxygen content of the specimen.

The present result shows the interrelation among mass transfer rate, extent of gas evolution and rotational speed in the solid dissolution process. Similar relationship has been observed by Sevinc and Elliott, ${ }^{9)}$ and Suzuki and Mori ${ }^{10}$ in the studies on the reduction of rotated solid $\mathrm{Cr}_{2} \mathrm{O}_{3}$ by liquid $\mathrm{Fe}-\mathrm{Cr}-\mathrm{C}$ alloys.

In the present case, at lower oxygen contents of the specimen, $\mathrm{CO}$ evolution may be slow and convective stirring by bubble formation weak. Hence, the mass transfer coefficient is dependent mainly on the rate of rotation. At higher oxygen contents, the rate of $\mathrm{CO}$ evolution becomes high and stirring by bubble formation strong. Hence, at lower rotational speeds, the mass transfer coefficient is controlled mainly by the extent of $\mathrm{CO}$ evolution. However, at higher rotational speeds, the effect of rotation on the rate of dissolution becomes predominant.

\section{Summary}

From the present study on the rates of dissolution of cylindrical iron specimens containing various amounts of oxygen into molten carbon-saturated iron alloys, it has been found that the dissolution rate is controlled by the rate of mass transfer across the boundary layer in the melt near the specimen surface.

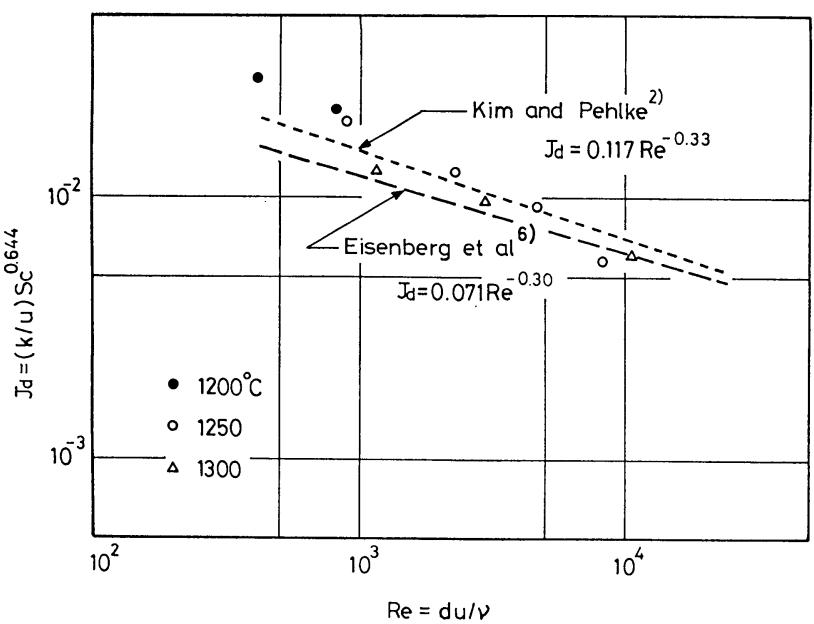

Fig. 7. Relation between mass transfer $J$-factor and Reynolds number for rotational dissolution of A1-killed iron cylinder into molten carbon-saturated iron at three temperatures.

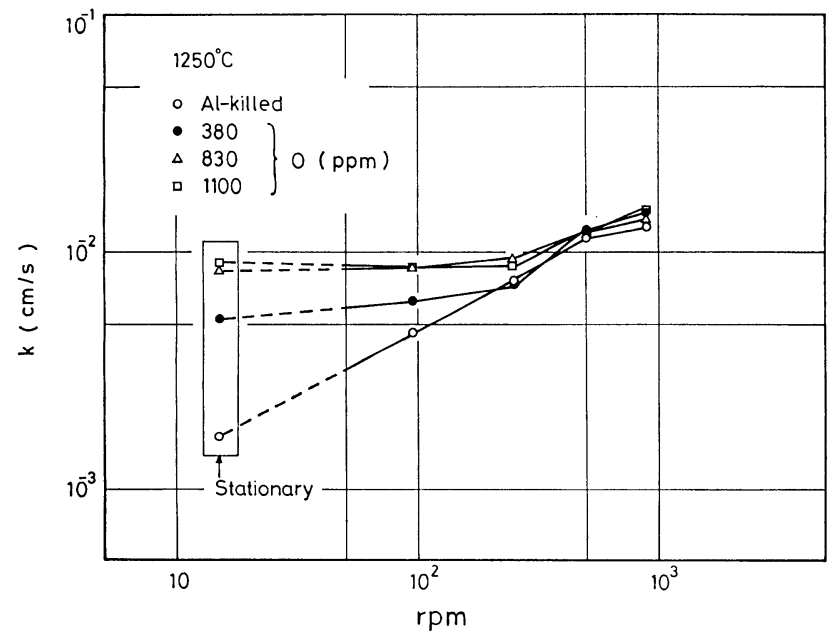

Fig. 8. Mass transfer coefficient vs. rpm for rotational dissolution of iron cylinders of various oxygen contents at $1250^{\circ} \mathrm{C}$.

When the specimens are stationary, oxygen in the iron specimen, that is, the evolution of CO markedly accelerates the dissolution rate. At lower temperatures, the mass transfer coefficient, $k$, increases with the volumetric evolution rate of $\mathrm{CO}, \dot{V}_{\mathrm{Co}}$, to a power of 0.3. At 1400 and $1450^{\circ} \mathrm{C}, k$ is proportional to $\dot{V}_{\text {co }}^{0.45}$. The lowest value of observed $k$ is $1.15 \times$ $10^{-3} \mathrm{~cm} / \mathrm{s}$ for aluminum-killed iron at $1200^{\circ} \mathrm{C}$, and the highest value is $8.4 \times 10^{-2} \mathrm{~cm} / \mathrm{s}$ for iron containing $0.96 \%$ oxygen at $1400{ }^{\circ} \mathrm{C}$. At 1200,1250 and $1300^{\circ} \mathrm{C}$, the mass transfer coefficient tends to decrease at high oxygen contents of the specimen.

In the case of rotational dissolution of iron specimens containing oxygen, at lower rpm the mass transfer coefficient is controlled mainly by the extent of $\mathrm{CO}$ evolution. At higher rpm $(\mathrm{rpm}>250)$, the effect of rotation becomes predominant.

\section{REFERENCES}

1) J. M. Lommel and B. Chalmers: Trans. TSM-AIME, 215 (1959), 499. 
2) Y.-U. Kim and R. D. Pehlke: Met. Trans., 5 (1974), 2527.

3) L.J.J. Janssen and J. G. Hoogland: Electrochemica Acta, 18 (1973), 543.

4) L.J.J.Janssen: Electrochemica Acta, 23 (1978), 81.

5) L. Sigrist, O. Dossenbach and N. Ibl: J. Heat Mass Transfer, 22 (1979), 1393.

6) M. Eisenberg, C. W. Tobias and C. R. Wilke: Chem. Eng.
Progr. Symp. Ser., 55 (1955), 1.

7) B. P. Burylev: Russ. J. Phys. Chem., 41 (1967), 53.

8) H. Nomura and K. Mori: Tetsu-to-Hagané, 55 (1969), 1134.

9) N. Sevinc and J.F. Elliott: Ironmaking Steelmaking, 3 (1976), 268.

10) K. Suzuki and K. Mori: Trans. ISIJ, 20 (1980), 607. 